Article

\title{
Facile solvothermal post-treatment to improve hydrothermal stability of mesoporous SBA-15 zeolite
}

\author{
Chenglong Zou a , Guanyu Sha ${ }^{\text {, }}$, Haifang Gu b , Yao Huang ${ }^{\text {, }}$ Guoxing Niu a,* \\ a Department of Chemistry, Fudan University, Shanghai 200433, China \\ b Department of Materials Science, Fudan University, Shanghai 200433, China
}

\section{A R T I C L E I N F O}

\section{Article history:}

Received 10 February 2015

Accepted 30 March 2015

Published 20 August 2015

\section{Keywords:}

Mesoporous material

SBA-15 zeolite

Hydrothermal stability

Solvothermal treatment

Dehydration

\begin{abstract}
A B S T R A C T
A simple and effective approach is demonstrated to improve the hydrothermal stability of mesoporous SBA-15 zeolite via a post-synthesis treatment of organic solvents, such as cyclohexane, toluene and $n$-butanol, at 157 or $190^{\circ} \mathrm{C}$ for $6-24 \mathrm{~h}$. After hydrothermal treatment at $800{ }^{\circ} \mathrm{C}$ for $12 \mathrm{~h}$ in $100 \%$ steam, the treated SBA-15 retained a well-ordered mesostructure, and retained high surface areas of $192-281 \mathrm{~m}^{2} / \mathrm{g}$. SBA-15 zeolite treated by cyclohexane at $190^{\circ} \mathrm{C}$ for $24 \mathrm{~h}$ showed the highest hydrothermal stability. The stabilization mechanism suggests that the solvothermal treatment has a significant promoting effect on dehydrating $\mathrm{Si}-\mathrm{OH}$ groups in silica walls to form stable $\mathrm{Si}(\mathrm{OSi})_{4}$ from $\mathrm{Si}(\mathrm{OSi})_{2}(\mathrm{OH})_{2}$ or $\mathrm{Si}(\mathrm{OSi})_{3} \mathrm{OH}$ groups. As a result, the wall defects after solvothermal treatment decrease, and the stability of silica is improved remarkably. This promoting effect strongly depends on the solvent properties, treatment temperature, and precursors of SBA-15 zeolite. The treatment by a nonpolar and low boiling point organic solvent displays the highest promoting effect on the calcined SBA-15 zeolite. This approach is simple, has low energy consumption and has potential application in the laboratory and for industry to prepare hydrothermally stable well-ordered mesoporous SBA-15 zeolite.
\end{abstract}

(C) 2015, Dalian Institute of Chemical Physics, Chinese Academy of Sciences. Published by Elsevier B.V. All rights reserved.

\section{Introduction}

Mesoporous silica, such as SBA-15, has attracted much attention because of their interesting mesostructure and wide application in catalysis as supports [1-5]. The ordered mesopores can improve the diffusion of bulk molecules in channels, catalytic activity, and selectivity. However, many catalytic reactions, such as oxidation, hydrogenation, dehydration, hydration, and Fischer-Tropsch synthesis, are often carried out in the presence of $\mathrm{H}_{2} \mathrm{O}$ or even in aqueous solution, and catalysts used in cracking are regenerated in steam at a high temperature. Therefore, high hydrothermal stability is an important feature of catalytic supports [6-9]. However, mesoporous silica has poor hydrothermal stability. When heated in aqueous solutions or steam for a long duration, the material suffers from the collapse of its ordered mesostructure and a corresponding loss of surface area [10]. Therefore, much research has focused on improving the hydrothermal stability using various approaches, such as removing surface $\mathrm{Si}-\mathrm{OH}$ groups by silylation [11-14] and F- ions [15-17] to form a hydrophobic surface, thickening mesopore walls by adding inorganic salts or using surfactants $[18,19]$, assembling from nanosized zeolite precursors or transferring zeolites to mesoporous materials [20-24], incorporating heteroatoms into the framework [25-28], and

\footnotetext{
* Corresponding author. Tel: +86-21-51630205; Fax: +86-21-51630307; E-mail: gxniu@fudan.edu.cn This work was financially supported by the National Basic Research Program of China (973 Program, 2010CB226901,2013CB934100) and the National Natural Science Foundation of China (20890123).

DOI: 10.1016/S1872-2067(15)60857-9 | http://www.sciencedirect.com/science/journal/18722067 | Chin. J. Catal., Vol. 36 , No. 8, August 2015
} 
enhancing the silica condensation of pore walls [29-32].

The silica condensation is an important factor to determine the hydrothermal stability of mesoporous silicas [29-36]. Zhang et al. [29] employed a carbon propping high-temperature treatment at $800{ }^{\circ} \mathrm{C}$ to increase the condensation degree. This approach showed superior hydrothermal stability in pure steam at $800{ }^{\circ} \mathrm{C}$ for $12 \mathrm{~h}$, but involved a relatively high energy consumption and complicated process. Du et al. [7] successfully synthesized hydrothermally stable mesoporous materials using fluorine-containing surfactants as templates at a high crystallization temperature of $150-220^{\circ} \mathrm{C}$. This success relies on fluorine-containing surfactants having a higher thermal stability than that of the triblock copolymer Pluronic P123, which is used as the backbone to make SBA-15. Thus, the mesopore walls were more condensed at higher crystallization temperatures. However, fluorine-containing surfactants are expensive and environmentally unfriendly, and their application is limited. Pan et al. [31] developed a facile and environmentally friendly approach to increase framework crosslinking using Pluronic P123 as a template. This approach employed a high-temperature hydrothermal crystallization (approximately $200{ }^{\circ} \mathrm{C}$ ), and the $\mathrm{pH}$ was adjusted between 1 and 3 to avoid decomposing the copolymer. The obtained mesoporous aluminosilicates retained an ordered mesostructure after treatment at $800{ }^{\circ} \mathrm{C}$ for $5 \mathrm{~h}$ in $15 \%$ steam with $\mathrm{N}_{2}$ gas ( $\left.45 \mathrm{~mL} / \mathrm{min}\right)$. However, no results for hydrothermal treatment at $800{ }^{\circ} \mathrm{C}$ in $100 \%$ steam were given. Therefore, there is potential to further design a simple, highly effective, low energy consumption, and environmentally friendly approach to promote silica condensation and improve the hydrothermal stability of mesoporous SBA-15 zeolite.

In this study, we propose a facile approach to enhance the silica condensation of mesoporous SBA-15 zeolite via a postsynthesis treatment of organic solvents at 157 or $190{ }^{\circ} \mathrm{C}$. The obtained SBA-15 zeolites have excellent hydrothermal stability. The effects of solvent, temperature, time, and SBA-15 precursors are investigated to discuss the stabilization mechanism.

\section{Experimental}

\subsection{Chemicals}

Triblock copolymer Pluronic $\mathrm{P} 123\left(\mathrm{EO}_{20} \mathrm{PO}_{70} \mathrm{EO}_{20}, M_{\mathrm{r}}=\right.$ 5800; Sigma-Aldrich, St. Louis, MO, USA), aluminum isopropoxide (Lingfeng Chemical Corp., Shanghai, China, analytical grade), tetraethyl orthosilicate (TEOS; Sigma-Aldrich; analytical grade 98\%), toluene, cyclohexane, $n$-butanol and hydrochloric acid (Shanghai Chemical Corp., Shanghai, China; analytical grade) were used as received without further purification.

\subsection{Synthesis of $S B A-15$}

Mesoporous SBA-15 was synthesized according to a previously published technique [37]. For a typical synthesis procedure, $25.0 \mathrm{~g}$ of $\mathrm{P} 123$ was dissolved in $750 \mathrm{~mL}$ of $\mathrm{HCl}$ solution (2 $\mathrm{mol} / \mathrm{L}$ ) at $35^{\circ} \mathrm{C}, 52.0 \mathrm{~g}$ of TEOS was added into the solution and hydrolyzed at $35^{\circ} \mathrm{C}$ for $12 \mathrm{~h}$ with vigorous stirring. The mixture was transferred into a Teflon vessel, sealed and heated at 100 ${ }^{\circ} \mathrm{C}$ for $48 \mathrm{~h}$. The resulting SBA-15 was filtrated, washed, dried at $100{ }^{\circ} \mathrm{C}$ for $4 \mathrm{~h}$ and calcined at $550{ }^{\circ} \mathrm{C}$ for $5 \mathrm{~h}$.

\subsection{Solvothermal treatment}

Calcined SBA-15 zeolite (10.0 g) was mixed with $50 \mathrm{~mL}$ of solvent, which was toluene, cyclohexane, $n$-butanol, or water, in a Teflon vessel, sealed and heated without stirring to temperature of 157 or $190^{\circ} \mathrm{C}$ for $3,6,12$, and $24 \mathrm{~h}$. After filtration, the samples were dried at $120^{\circ} \mathrm{C}$ for $4 \mathrm{~h}$, and calcined at $550{ }^{\circ} \mathrm{C}$ in air for $5 \mathrm{~h}$. They were named $\mathrm{S} 15(x)-T(t)$, where $x$ is T, C, B, or $\mathrm{H}$ corresponding to toluene, cyclohexane, $n$-butanol, or water, respectively, $T$ is the treatment temperature of 157 or $190{ }^{\circ} \mathrm{C}$, and $t$ is the treatment time of $3,6,12$, or $24 \mathrm{~h}$.

\subsection{Evaluation of hydrothermal stability}

All samples (0.3 g) were pressed into discs at $1.0 \mathrm{MPa}$ and put into a tube furnace. After they were heated to $800{ }^{\circ} \mathrm{C}, 100 \%$ steam with gas flow (1000 $\mathrm{mL} / \mathrm{min})$ was introduced into the furnace, and the duration of hydrothermal treatment was $12 \mathrm{~h}$.

\subsection{Characterization}

X-ray diffraction (XRD) patterns were recorded on a Bruker D8 X-ray diffractometer (Karlsruhe, Germany) with Ni-filtered $\mathrm{Cu} K_{\alpha}$ radiation $(40 \mathrm{kV}, 40 \mathrm{~mA})$. Nitrogen adsorption-desorption isotherms were measured at $-196{ }^{\circ} \mathrm{C}$ with a Micromeritics Tristar 3000 analyzer. The Brunauer-Emmett-Teller (BET) method was used to calculate the specific surface areas using adsorption data in a relative pressure range from 0.05 to 0.2 . The pore size distributions were derived from the adsorption branches of the isotherms using the Barrett-Joyner-Halenda model. The total pore volume $V_{\mathrm{t}}$ was estimated from the amount adsorbed at a relative pressure $p / p_{0}$ of 0.995 . The true density of SBA-15 zeolite was measured by Beijing JWGB Sci. \& Tech. Co., Ltd on a BT122T-B pore size analyzer. Before measuring, all samples were degassed at $250{ }^{\circ} \mathrm{C}$ for 6 h. ${ }^{29} \mathrm{Si} \mathrm{NMR}$ spectra were performed on a Bruker AVANCE AV $400 \mathrm{MHz}$ spectrometer at a frequency of $59.621 \mathrm{MHz}$, a recycling delay of $600 \mathrm{~s}$, a radiation frequency intensity of $62.5 \mathrm{kHz}$, and a reference sample of $\left[\left(\mathrm{CH}_{3}\right)_{3} \mathrm{SiO}_{8} \mathrm{Si}_{8} \mathrm{O}_{12}\right.$. Transmission electron microscopy (TEM) and scanning electron microscopy (SEM) images were taken using a JEOL 2011 microscope operated at 200 $\mathrm{kV}$ and a Philips XL30, respectively. FTIR spectra were recorded on a Nicolet FTIR Avatar 360 at $120^{\circ} \mathrm{C}$. The samples were pressed directly in a mold without adding any other additives, such as $\mathrm{KBr}$, and pre-treated at $450{ }^{\circ} \mathrm{C}$ in a $1.0 \times 10^{-4} \mathrm{~Pa}$ vacuum for $5 \mathrm{~h}$.

\section{Results and discussion}

\subsection{Hydrothermal stability}

The calcined SBA-15 without solvothermal treatment displayed three resolved diffraction peaks at $2 \theta=0.86^{\circ}$ and be- 
tween $1.5^{\circ}$ and $2.0^{\circ}$, corresponding to the (100), (110) and (200) reflections of a 2D hexagonal mesostructure (Fig. 1(a-1)). The sample showed a typical type IV isotherm with a $\mathrm{H}_{1}$-type hysteresis loop (Fig. 2(a-1)), a high surface area of $745 \mathrm{~m}^{2} / \mathrm{g}$, a large pore volume of $1.27 \mathrm{~cm}^{3} / \mathrm{g}$, uniform pores of $5.83 \mathrm{~nm}$ in diameter (Table 1), and a well-ordered hexagonal mesostructure with a fiber-shape morphology (Fig. 3A(a) and Fig. 4A(a)). These results suggest that SBA-15 has a well-ordered mesostructure. When the untreated SBA-15 sample was treated hydrothermally at $800{ }^{\circ} \mathrm{C}$ for $12 \mathrm{~h}$ in $100 \%$ steam, no diffraction peaks were shown in the XRD spectrum (Fig. 1(b-1)). There was no $\mathrm{H}_{1}$-type hysteresis loop in the $\mathrm{N}_{2}$ adsorption isotherm (Fig. 2(b-1)). The surface area decreased drastically to 71 from $745 \mathrm{~m}^{2} / \mathrm{g}$ (Table 1), corresponding to a surface area loss of approximately $90 \%$ after hydrothermal treatment. The SEM image shows that the original fiber-shape morphology was lost and became glass-like (Fig. 3A(b)). There were no ordered mesopores observed in the TEM image (Fig. 4A(b)). These results suggest that the pore structure of the calcined SBA-15 was broken completely because of the severe hydrothermal treatment of $100 \%$ steam at $800{ }^{\circ} \mathrm{C}$ for $12 \mathrm{~h}$.

When the calcined SBA-15 was treated in cyclohexane at $190^{\circ} \mathrm{C}$ for $24 \mathrm{~h}$, the XRD pattern showed that all the diffraction

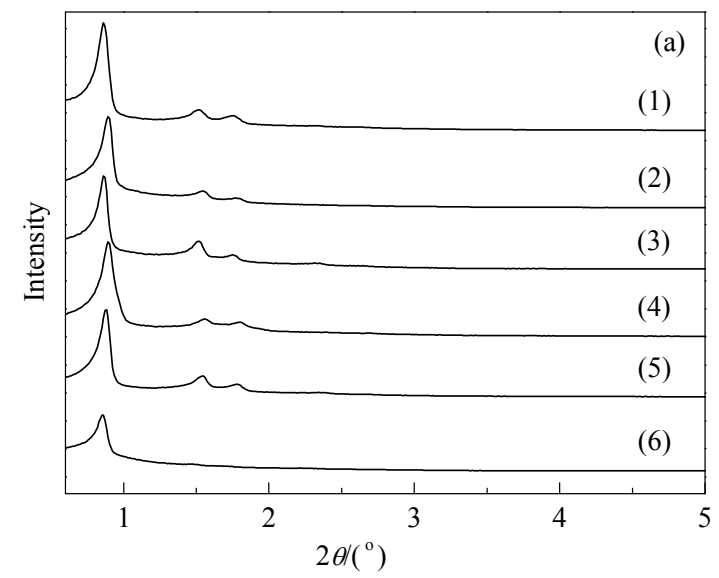

Fig. 1. XRD patterns of SBA-15 (1), S15(C)-190(24) (2), S15(T)-190(24) (3), S15(B)-190(24) (4), S15(C)-157(24) (5) and S15(H)-190(24) (6) before (a) and after (b) treated hydrothermally at $800^{\circ} \mathrm{C}$ for $12 \mathrm{~h}$ in $100 \%$ steam.

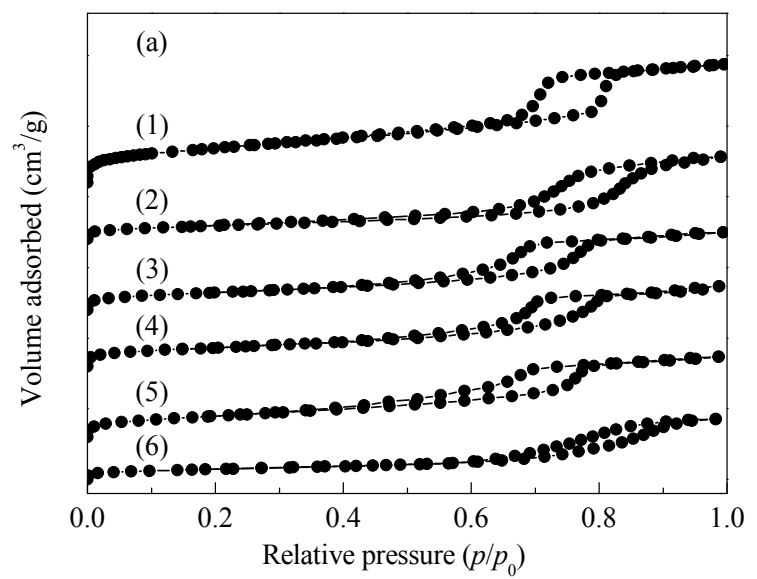

peaks of sample $\mathrm{S} 15(\mathrm{C})-190(24)$ at $2 \theta=0.86^{\circ}-2.0^{\circ}$ were resolved (Fig. 1(a-2)). The type IV adsorption isotherms showed a H1-type hysteresis loop (Fig. 2(a-2)), and the fiber-shape morphology (Fig. 3B(a)) was retained. Well-ordered and slightly larger mesopores than those before cyclohexane treatment were observed clearly in the TEM image (Fig. 4B(a)). These results indicate that the cyclohexane treatment does not damage the mesostructure of SBA-15 zeolite. As shown in Table 1, the surface area of sample S15(C)-190(24) decreased to 355 $\mathrm{m}^{2} / \mathrm{g}$ from that of the untreated SBA-15 sample at $745 \mathrm{~m}^{2} / \mathrm{g}$, as well as a decrease in pore volume to 1.03 from $1.27 \mathrm{~cm}^{3} / \mathrm{g}$. This loss corresponded to a $52 \%$ reduction of surface area and $19 \%$ reduction of pore volume after cyclohexane treatment. The micropore surface area and pore volume were reduced to 55 from $154 \mathrm{~m}^{2} / \mathrm{g}$ and 0.13 from $0.27 \mathrm{~cm}^{3} / \mathrm{g}$, respectively, which were a $64 \%$ loss of micropore surface area and a $52 \%$ loss of micropore pore volume. The cyclohexane treatment affected the microstructure of SBA-15 more than the mesostructure. Compared with SBA-15, sample S15(C)-190(24) showed a lower lattice constant of $11.47 \mathrm{~nm}$, a larger pore at $7.99 \mathrm{~nm}$ in diameter, and a thinner wall thickness of $3.48 \mathrm{~nm}$, suggesting that the walls had shrunk and become denser during cyclohexane treatment. This shrinkage is also reflected by the true

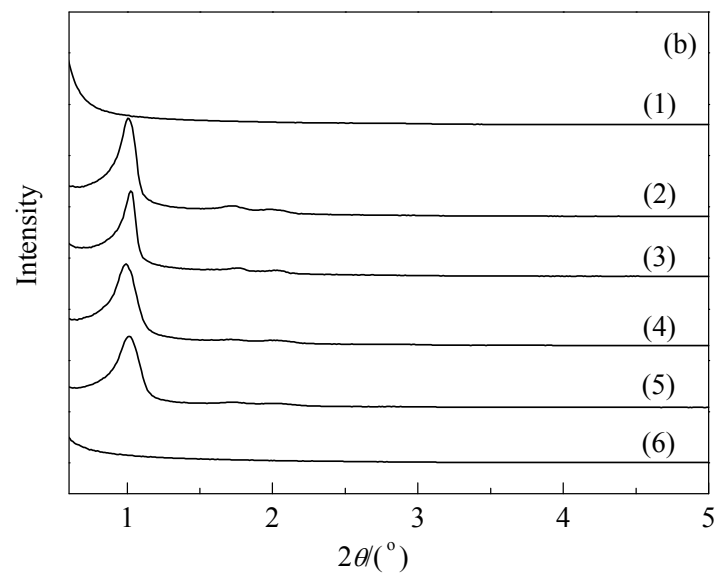

(b)

(2)

(3)

(4)

(6) 
Table 1

Structure parameters of the mesoporous SBA-15 zeolite before and after hydrothermal treated at $800{ }^{\circ} \mathrm{C}$ for $12 \mathrm{~h}$ in $100 \%$ steam.

\begin{tabular}{|c|c|c|c|c|c|c|c|c|c|c|}
\hline Treatment & Sample & $\begin{array}{c}A_{\mathrm{BET}} \\
\left(\mathrm{m}^{2} / \mathrm{g}\right)\end{array}$ & $\begin{array}{c}A_{\text {micro }} \\
\left(\mathrm{m}^{2} / \mathrm{g}\right)\end{array}$ & $\begin{array}{c}V_{\mathrm{BJH}} \\
\left(\mathrm{cm}^{3} / \mathrm{g}\right)\end{array}$ & $\begin{array}{c}V_{\text {mic }} \\
\left(\mathrm{cm}^{3} / \mathrm{g}\right)\end{array}$ & $\begin{array}{c}D_{\mathrm{BJH}} \\
(\mathrm{nm})\end{array}$ & $\begin{array}{c}2 \theta \\
\left({ }^{\circ}\right)\end{array}$ & $\begin{array}{c}A_{0} \\
(\mathrm{~nm})\end{array}$ & $\begin{array}{l}d_{\text {wall }} \\
(\mathrm{nm})\end{array}$ & $\begin{array}{c}\rho \\
\left(\mathrm{g} / \mathrm{cm}^{3}\right) \\
\end{array}$ \\
\hline \multirow[t]{6}{*}{ Before treatment } & SBA-15 & 745 & 154 & 1.27 & 0.27 & 5.83 & 0.86 & 11.86 & 6.03 & 1.88 \\
\hline & S15(C)-190(24) & 355 & 55 & 1.03 & 0.13 & 7.99 & 0.89 & 11.47 & 3.48 & 2.70 \\
\hline & S15(T)-190(24) & 477 & 61 & 0.96 & 0.18 & 6.74 & 0.86 & 11.86 & 5.12 & 2.92 \\
\hline & S15(B)-190(24) & 477 & 76 & 1.00 & 0.19 & 6.82 & 0.89 & 11.47 & 4.65 & 2.92 \\
\hline & S15(C)-157(24) & 546 & 43 & 1.02 & 0.20 & 7.35 & 0.88 & 11.60 & 4.25 & 2.81 \\
\hline & $\mathrm{S} 15(\mathrm{H})-190(24)$ & 255 & 41 & 0.72 & 0.10 & 7.13 & 0.86 & 11.86 & 4.73 & - \\
\hline \multirow[t]{6}{*}{ After treatment } & SBA-15 & 71 & 2 & 0.26 & 0.02 & 2.45 & - & - & - & - \\
\hline & S15(C)-190(24) & 281 & 51 & 0.54 & 0.10 & 5.72 & 1.00 & 10.20 & 5.48 & - \\
\hline & S15(T)-190(24) & 239 & 39 & 0.48 & 0.09 & 5.65 & 1.02 & 10.00 & 4.45 & - \\
\hline & S15(B)-190(24) & 192 & 16 & 0.43 & 0.07 & 5.89 & 0.99 & 10.31 & 4.42 & - \\
\hline & S15(C)-157(24) & 256 & 26 & 0.52 & 0.09 & 5.33 & 1.01 & 10.11 & 4.78 & - \\
\hline & $\mathrm{S} 15(\mathrm{H})-190(24)$ & 54 & 1 & 0.20 & 0.02 & 2.43 & - & - & - & - \\
\hline
\end{tabular}

$\rho$. the true density of sample.

densities shown in Table 1. Sample S15(C)-190(24) showed a true density of $2.70 \mathrm{~g} / \mathrm{cm}^{3}$, which was larger than that of SBA-15 (1.88 g/ $\left.\mathrm{cm}^{3}\right)$. The larger pore sizes of SBA-15 after cyclohexane treatment is beneficial for the diffusion of bulk reactants when used in catalysis, and may be an additional benefit of cyclohexane treatment.

The diffraction peaks were retained when S15(C)-190(24) sample was treated hydrothermally at $800{ }^{\circ} \mathrm{C}$ for $12 \mathrm{~h}$ in $100 \%$ steam (Fig. 1(b-2)), and a clear $\mathrm{H}_{1}$-type hysteresis loop was shown in Fig. 2(b-2). The fiber-shape morphology was main-

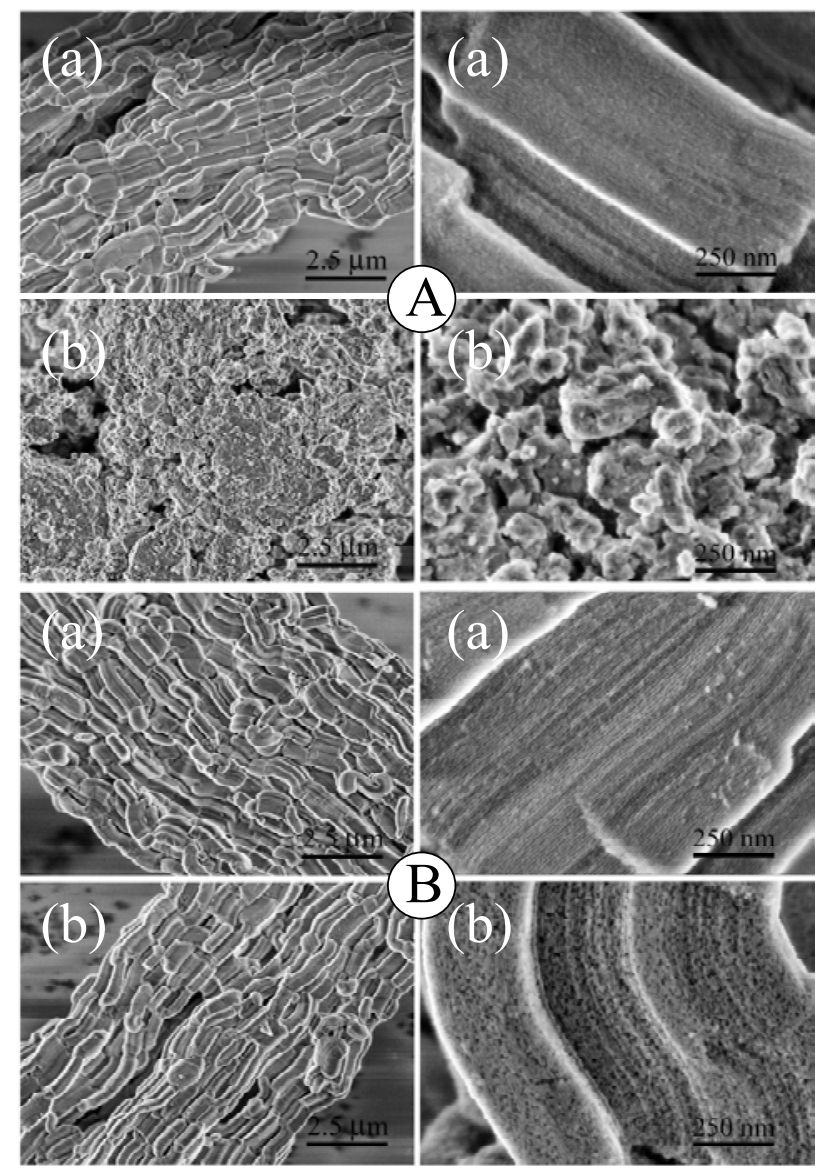

Fig. 3. SEM images of SBA-15 (A) and S15(C)-190(24) (B) before (a) and after (b) treated hydrothermally at $800{ }^{\circ} \mathrm{C}$ for $12 \mathrm{~h}$ in $100 \%$ steam. tained the same as that before hydrothermal treatment, and the bundles were still close together (Fig. 3B(b)). The ordered mesostructure was observed clearly in Fig. 4B(b), whereas a few irregular large-sized pores appeared on the walls, which may be a result of the steam. These results suggest that the cyclohexane treatment of SBA-15 is a promoting effect on improving hydrothermal stability. Moreover, cyclohexane can be recycled and was used three times without any purification. The obtained samples displayed the same properties of mesostructure and high hydrothermal stability as those made using fresh cyclohexane. Furthermore, the solvent of cyclohexane can be recovered and purified easily using distillation.

\subsection{Effects of solvents and temperature}

Both samples of S15(T)-190(24) and S15(B)-190(24) presented well-ordered mesostructure as shown in Fig. 1(a-3) and (a-4) and Fig. 2(a-3) and (a-4), and surface areas of $477 \mathrm{~m}^{2} / \mathrm{g}$ (Table 1). The surface areas were larger than that of S15(C)-190(24), which was $355 \mathrm{~m}^{2} / \mathrm{g}$, suggesting that cyclohexane treatment affected the structure of silica more than toluene or butanol treatments under the same conditions. When treated hydrothermally at $800{ }^{\circ} \mathrm{C}$ for $12 \mathrm{~h}$ in $100 \%$ steam, S15(T)-190(24) and S15(B)-190(24) samples also retained ordered mesostructures as confirmed in Fig. 1(b-3) and

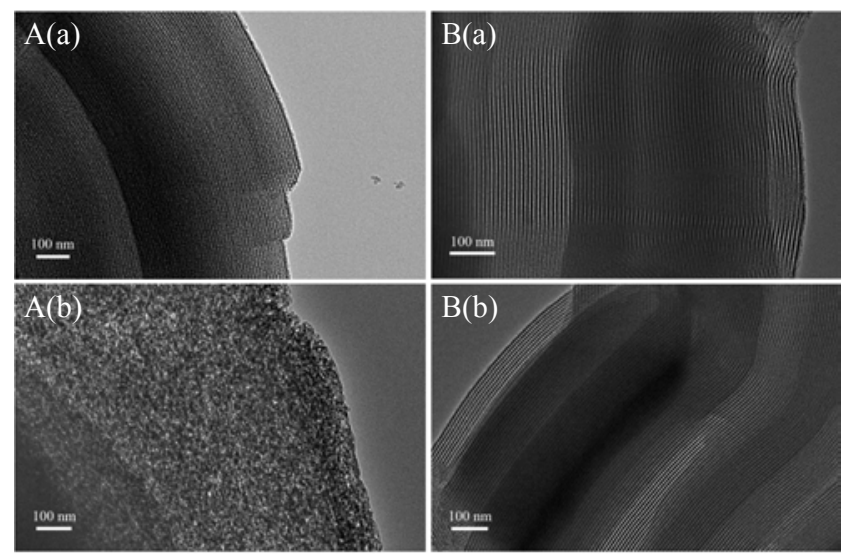

Fig. 4. TEM images of SBA-15 (A) and S15(C)-190(24) (B) before (a) and after (b) treated hydrothermally at $800{ }^{\circ} \mathrm{C}$ for $12 \mathrm{~h}$ in $100 \%$ steam. 
(b-4) and Fig. 2(b-3) and (b-4), but displayed lower surface areas of 239 and $192 \mathrm{~m}^{2} / \mathrm{g}$, respectively, than sample S15(C)-190(24), which was $281 \mathrm{~m}^{2} / g$. These results suggest that the cyclohexane treatment has the largest effect on promoting the hydrothermal stability of SBA-15. Sample S15(C)-157(24) showed an improved hydrothermal stability after treatment at $800{ }^{\circ} \mathrm{C}$ for $12 \mathrm{~h}$ in $100 \%$ steam. The well-ordered mesostructure was retained (Fig. 1(b-5) and Fig. 2(b-5)), and a high surface area of $256 \mathrm{~m}^{2} / \mathrm{g}$ was recorded; however, the surface area was slightly smaller than that of sample S15(C)-190(24) (Table 1). This result suggests that the treatment temperature was important in promoting the hydrothermal stability of zeolite.

$\mathrm{H}_{2} \mathrm{O}$ was chosen as a treatment solvent and sample S15(H)-190(24) displayed only a small diffraction peak of the (100) reflection at $2 \theta=0.86^{\circ}$. There were no peaks of the (110) and (200) reflections, which would be observed at $2 \theta=$ $1.5^{\circ}-2.0^{\circ}$ (Fig. 1(a-6)). The $\mathrm{H}_{1}$-type hysteresis loop became smaller than those of the other solvothermal treatment samples (Fig. 2(a-6)). These results indicate that most of the ordered mesostructure had lost during $\mathrm{H}_{2} \mathrm{O}$ treatment. Moreover, after the sample was treated hydrothermally at $800{ }^{\circ} \mathrm{C}$ for $12 \mathrm{~h}$ in $100 \%$ steam, the diffraction peak and hysteresis loop were no longer present as shown in Fig. 1(b-6) and Fig. 2(b-6), respectively. The surface area decreased to $54 \mathrm{~m}^{2} / \mathrm{g}$. These results suggest that the hydrothermal stability of S15(H)-190(24) sample is not improved by $\mathrm{H}_{2} \mathrm{O}$ treatment.

\subsection{Effect of duration}

The calcined SBA- 15 was treated in toluene at $190{ }^{\circ} \mathrm{C}$ for 3 , 6,12 , and $24 \mathrm{~h}$, and the XRD patterns and $\mathrm{N}_{2}$ sorption isotherms confirm that all the samples retained a well-ordered mesostructure (figures not shown). However, their BET surface areas were lower than the untreated SBA-15, and the area decreased with the increase of time until $6 \mathrm{~h}$, then kept around $480 \mathrm{~m}^{2} / \mathrm{g}$, as shown in Fig. 5(1). This result suggests that the structure change in SBA-15 caused by toluene treatment mainly happens within the first $6 \mathrm{~h}$. As the samples were hydro-

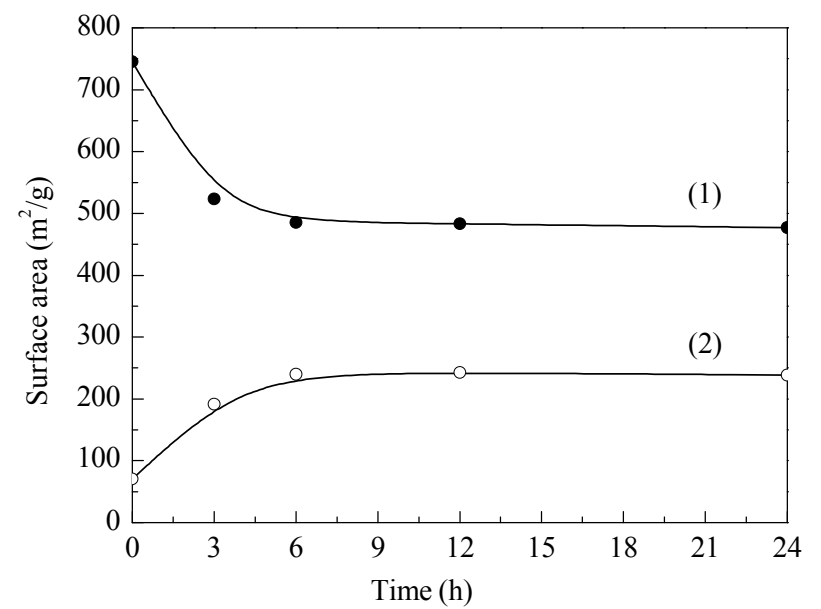

Fig. 5. BET surface areas of SBA-15 samples treated with toluene at 190 ${ }^{\circ} \mathrm{C}$ against the time before (1) and after (2) treated hydrothermally at $800{ }^{\circ} \mathrm{C}$ for $12 \mathrm{~h}$ in $100 \%$ steam. thermally treated at $800{ }^{\circ} \mathrm{C}$ for $12 \mathrm{~h}$ in $100 \%$ steam, the surface area increased with the increase of time at first, then maintained at approximately $240 \mathrm{~m}^{2} / \mathrm{g}$ after $6 \mathrm{~h}$ (Fig. 5(2)). Obviously, the toluene treatment in the first $6 \mathrm{~h}$ played a more important role in improving the hydrothermal stability. The results indicate that the improved hydrothermal stability results from the effect of toluene treatment on the structure of silica. Because the improved effect is most obvious in the first $6 \mathrm{~h}$, the treatment time can be shortened, saving energy and increasing the efficiency of this approach.

\section{4. ${ }^{29}$ Si NMR spectra}

As shown in Fig. 6, all the samples displayed three peaks centered at $\delta=-90,-100$, and -110 , which were attributed to silicon atoms with two siloxane bands and two silanol groups $\left[(\mathrm{SiO})_{2} * \mathrm{Si}(\mathrm{OH})_{2}\left(\mathrm{Q}_{2}\right)\right]$, three siloxane bonds and one silanol group $\left[\left(\mathrm{SiO}_{3}{ }^{*} \mathrm{SiOH}\left(\mathrm{Q}_{3}\right)\right]\right.$, and four siloxane bonds, $(\mathrm{SiO})_{4} * \mathrm{Si}\left(\mathrm{Q}_{4}\right)$, respectively [38]. The $\mathrm{Q}_{4} /\left(\mathrm{Q}_{3}+\mathrm{Q}_{2}\right)$ ratios were $0.34,0.56,0.50$, and 0.54, corresponding to untreated SBA-15, S15(C)-190(24), S15(T)-190(24), and S15(C)-157(24), respectively. The ratio increased after SBA-15 was treated with cyclohexane or toluene, suggesting that solvothermal treatment can promote the crosslinking of amorphous walls to form $\mathrm{Si}(\mathrm{OSi})_{4}$ from $\mathrm{Si}(\mathrm{OSi})_{2}(\mathrm{OH})_{2}$ or $\mathrm{Si}(\mathrm{OSi})_{3} \mathrm{OH}$, and increase the silica condensation degree of the walls. The $\mathrm{Q}_{4} /\left(\mathrm{Q}_{3}+\mathrm{Q}_{2}\right)$ ratios correlated with the surface areas of samples treated hydrothermally at $800{ }^{\circ} \mathrm{C}$ for $24 \mathrm{~h}$ in $100 \%$ steam. This result suggests that the crosslinking of amorphous walls by solvothermal treatment is important in improving the hydrothermal stability of SBA-15. The $\mathrm{Q}_{4} /\left(\mathrm{Q}_{3}+\mathrm{Q}_{2}\right)$ ratio of $\mathrm{S} 15(\mathrm{~B})-190(24)$ sample was 0.36 , which was slightly higher than that of SBA-15, but much lower than those of S15(T)-190(24) and S15(C)-190(24). This result suggests that $n$-butanol treatment has a lower promoting effect on the crosslinking of walls than those of toluene and cyclohexane treatments. However, sample S15(H)-190(24) showed the highest $\mathrm{Q}_{4} /\left(\mathrm{Q}_{3}+\mathrm{Q}_{2}\right)$ ratio $(0.6)$ and the highest crosslinking but the worst hydrothermal stability. This contradiction is discussed below.

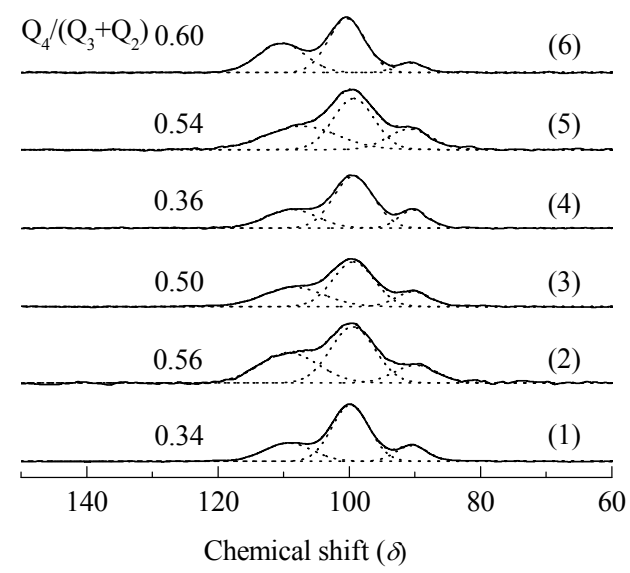

Fig. 6. ${ }^{29} \mathrm{Si}$ NMR spectra of SBA-15 (1), S15(C)-190(24) (2), S15(T)-190(24) (3), S15(B)-190(24) (4), S15(C)-157(24) (5) and S15(H)-190(24) (6). 


\subsection{IR spectra}

In Fig. 7, all the samples show an intense hydroxyl band at $3740 \mathrm{~cm}^{-1}$, which results from the vibration of free $\mathrm{Si}-\mathrm{OH}$ groups on the walls of SBA-15. Compared with SBA-15, the spectra of S15(C)-190(24), S15(T)-190(24), S15(B)-190(24), S15(C)-157(24), and S15(H)-190(24) displayed weaker hydroxyl band intensity, indicating a hydroxyl group loss of $59.9 \%, 37.5 \%$, 54.9\%, 58.1\%, and $62.3 \%$, respectively. This decrease may result from two possibilities, the dehydration of $\mathrm{Si-OH}$ groups to form $\mathrm{Si}-\mathrm{O}-\mathrm{Si}$ bands, or the reaction of $\mathrm{Si}-\mathrm{OH}$ groups with other active reactants, such as alcohols and acids. The S15(T)-190(24), S15(C)-157(24), and S15(C)-190(24) samples only used nonpolar and inert solvents of toluene and cyclohexane. Therefore, the only reason for the decrease in hydroxyl groups in these samples is dehydration between $\mathrm{Si-OH}$ groups and crosslinking, which is in agreement with the ${ }^{29} \mathrm{Si}$ NMR results. The IR spectra of samples that were not calcined after solvothermal treatment showed that the S15(B)-190(24) sample displayed C-H vibration bands at 2850-3250 $\mathrm{cm}^{-1}$ (figure not shown). However, no C-H bands appeared in the spectra of S15(T)-190(24) and S15(C)-190(24) samples. This result suggests that some $\mathrm{Si}-\mathrm{OH}$ groups on the walls reacted to form $\mathrm{Si}-\mathrm{O}-\mathrm{C}_{4} \mathrm{H}_{9}$ during $n$-butanol treatment at high temperature. The formation of $\mathrm{Si}-\mathrm{O}-\mathrm{C}_{4} \mathrm{H}_{9}$ bands decreases dehydration between $\mathrm{Si}-\mathrm{OH}$ groups to form $\mathrm{Si}-\mathrm{O}-\mathrm{Si}$ bands. Therefore, S15(B)-190(24) has a low ratio of $\mathrm{Q}_{4} /\left(\mathrm{Q}_{3}+\mathrm{Q}_{2}\right)$ but a weak intensity of hydroxyl bands.

\subsection{Effect of the SBA-15 precursors and solvent amount}

Three precursors to solvothermal treated SBA-15 were calcined, as-made (not calcined) and washed (P123 surfactants were removed by washing with ethanol and not calcined) SBA-15 samples. They were treated in toluene at $190{ }^{\circ} \mathrm{C}$ for 12 $\mathrm{h}$, and hydrothermally at $800{ }^{\circ} \mathrm{C}$ for $12 \mathrm{~h}$ in $100 \%$ steam. S15(T)-190(12) sample displayed a high surface area of 242 $\mathrm{m}^{2} / \mathrm{g}$. However, S15(T)-A-190(12) sample, which was from the as-made SBA-15, recorded a $148 \mathrm{~m}^{2} / \mathrm{g}$ surface area. S15(T)-B-190(12) sample, which was from the washed SBA-15,

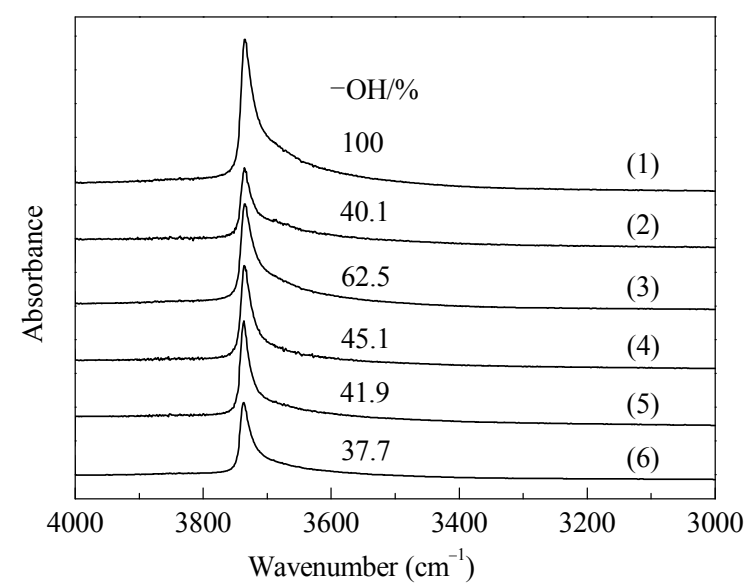

Fig. 7. IR spectra of SBA-15 (1), S15(C)-190(24) (2), S15(T)-190(24) (3), S15(B)-190(24) (4), S15(C)-157(24) (5) and S15(H)-190(24) (6). only recorded a $45 \mathrm{~m}^{2} / \mathrm{g}$ surface area, which was as low as that of SBA-15 without toluene treatment. The toluene treatment displayed the highest stability promoting effect on the precursor of calcined SBA-15. The differences were because the structure change of three precursors was not the same at the introduction of liquid at high pressure. A detailed explanation is given below.

The solvent amount was important in improving hydrothermal stability. S15(T)-C-190(12) sample, obtained by treating $10.0 \mathrm{~g}$ of the calcined SBA-15 with $5 \mathrm{~mL}$ of toluene instead of $50 \mathrm{~mL}$ at $190{ }^{\circ} \mathrm{C}$ for $12 \mathrm{~h}$, displayed a lower hydrothermal stability than S15(T)-190(12). After hydrothermal treatment at $800{ }^{\circ} \mathrm{C}$ for $12 \mathrm{~h}$ in $100 \%$ steam, the sample only retained a 187 $\mathrm{m}^{2} / \mathrm{g}$ surface area, which was lower than that of S15(T)-190(12) (242 $\left.\mathrm{m}^{2} / \mathrm{g}\right)$. Ten grams of SBA-15 sample has $12.7 \mathrm{~cm}^{3}$ of pore volume, and all the pores cannot be filled by 5 $\mathrm{mL}$ of toluene liquid, but it can be filled by toluene gas. Thus, the liquid at a high pressure has a higher promoting effect than gas, even when both pressures are the same.

\subsection{Discussion}

During the solvothermal treatment of SBA-15, high temperature, high pressure, and solvent type are important factors to improve hydrothermal stability. In a closed vessel, the organic solvent can auto-generate a high pressure at a high temperature, such as $0.64 \mathrm{MPa}$ for toluene at $190^{\circ} \mathrm{C}$, and $1.13 \mathrm{MPa}$ and $0.83 \mathrm{MPa}$ for cyclohexane at $190{ }^{\circ} \mathrm{C}$ and $157{ }^{\circ} \mathrm{C}$, respectively [39]. The introduced liquid at a high pressure exerts a strong pressure on the pore walls of SBA-15, and forces nearby $\mathrm{Si}-\mathrm{OH}$ groups close together. Thus, the hydroxyl groups, which were originally unable to dehydrate because of the separating distance, have opportunities to form stable $\mathrm{Si}-\mathrm{O}-\mathrm{Si}$ bonds at high temperatures. Thus, the silica walls are crosslinked better, and the defects decrease, as shown in Scheme 1. As a result, the hydrothermal stability of SBA-15 improves remarkably.

Among the solvents tested, the auto-generated pressure of cyclohexane at $190{ }^{\circ} \mathrm{C}$ is the highest, and thus the walls of SBA-15 would be subject to the highest pressure and increase the dehydration of Si-OH groups. Therefore, S15(C)-190(24) displays the highest hydrothermal stability, compared with that of S15(C)-157(24) and S15(T)-190(24).

During $n$-butanol treatment, the solvent can react with some $\mathrm{Si}-\mathrm{OH}$ groups to form $\mathrm{Si}-\mathrm{O}-\mathrm{C}_{4} \mathrm{H}_{9}$ groups. This formation is detrimental to the dehydration of $\mathrm{Si}-\mathrm{OH}$ groups, resulting in poor crosslinking. Though the surface becomes hydrophobic owing to the formation of $\mathrm{Si}-\mathrm{O}-\mathrm{C}_{4} \mathrm{H}_{9}$ groups, $\mathrm{Si}-\mathrm{O}-\mathrm{C}_{4} \mathrm{H}_{9}$ groups are not stable and may revert to $\mathrm{Si}-\mathrm{OH}$ groups when the sample is calcined in air or hydrothermally treated at $800{ }^{\circ} \mathrm{C}$. Therefore, the $n$-butanol treatment shows less stabilization on SBA-15 than that of toluene or cyclohexane treatments. S15(H)-190(24) sample shows increased crosslinking but does not improve hydrothermal stability because the crosslinking collapses the ordered mesostructure.

Three precursors of SBA-15 were evaluated using toluene treatment. For the calcined SBA-15, the calcining process removing P123 surfactants before solvent treatment may have an 


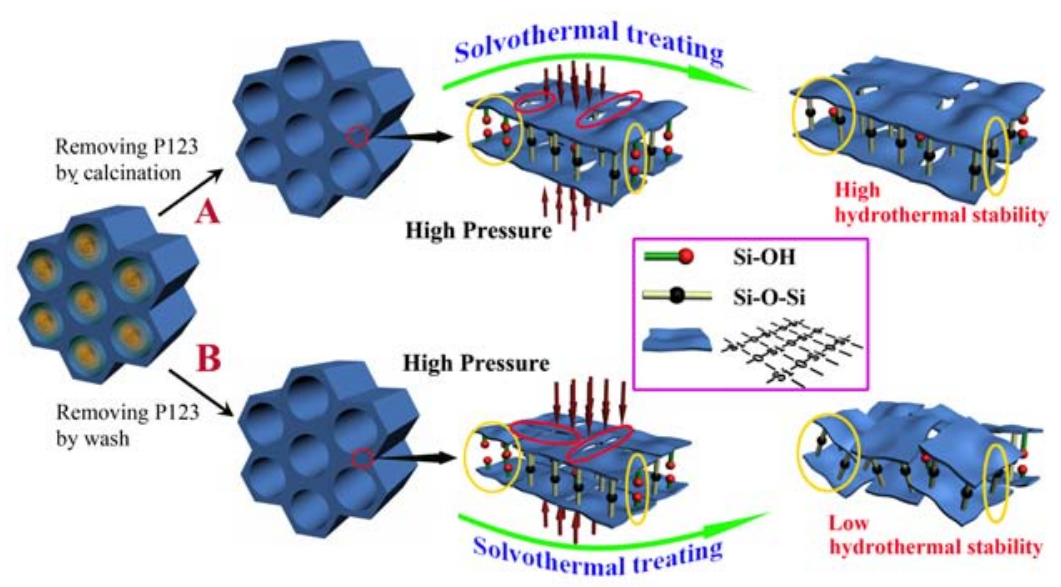

Scheme 1. Stabilization mechanism of the solvothermal treatment on SBA-15.

effect on the crosslinking of silica and the formation of integrated stabilized walls over a large region (Route A in Scheme 1). The stabilized walls can withstand the introduction of a solvent at high pressure and retain the ordered structure. Thus, the dehydration of free $\mathrm{Si}-\mathrm{OH}$ groups, caused by the solvothermal treatment, has a significant role on stabilizing the calcined SBA-15 and improving hydrothermal stability. However, for washed SBA-15, no further crosslinking can take place as the P123 surfactants were removed. The walls may only be crosslinked in scattered small regions, which can be distorted by the introduction of solvents at a high pressure during the solvothermal treatment and cause disorder in the walls (Route $B$ in Scheme 1). The disordered walls are not stable and collapse in the harsh hydrothermal treatment. Thus, the solvothermal treatment shows no stabilization effect on the washed SBA-15. Though the as-made SBA-15 has the same crosslinking of walls as the washed SBA-15, its walls are supported by P123 molecules. This supporting effect strengthens the walls of as-made SBA-15, and they do not distort as much as that of the washed SBA-15 after the introduction of a solvent at a high pressure. Therefore, the toluene treatment displays a better stabilization effect on the as-made SBA-15 than on the washed SBA-15, but worse one than on the calcined SBA-15.

Because the pores of SBA-15 are only filled by toluene in the gas phase at a high pressure, and not by toluene liquid, the gas can penetrate easily through the pores of the walls and into the bulk of SBA-15, resulting in a decrease of pressure difference between the inner and outer walls. As a result, the pressure forcing $\mathrm{Si}-\mathrm{OH}$ groups close together is reduced, and the promoting effect of solvothermal treatment is also reduced.

\section{Conclusions}

Solvothermal treatment displays encouraging results for improving the hydrothermal stability of SBA-15 zeolite. SBA-15 treated by cyclohexane at $190{ }^{\circ} \mathrm{C}$ for $24 \mathrm{~h}$ can maintain the ordered mesostructure well, and retain a high surface area of 281 $\mathrm{m}^{2} / \mathrm{g}$ after it was treated hydrothermally at $800{ }^{\circ} \mathrm{C}$ for $12 \mathrm{~h}$ in $100 \%$ steam. The promoting effect of solvothermal treatment is closely related to the temperature, solvent properties, and precursors of SBA-15 zeolite. This approach only requires a low-handling temperature and inexpensive solvents, which can be recovered and purified easily by distillation. Therefore, this approach is low cost, low energy consumption and has potential application to prepare hydrothermally stable and ordered mesoporous silica in the laboratory and for industry.

\section{References}

[1] Klimova T E, Valencia D, Mendoza-Nieto J A, Hernandez-Hipolito P. J Catal, 2013, 304: 29

[2] Parlett C M A, Keshwalla P, Wainwright S G, Bruce D W, Hondow N S, Wilson K, Lee A F. ACS Catal, 2013, 3: 2122

[3] Liu H M, Li Y M, Wu H, Yang W W, He D H. Chin J Catal (刘会敏, 李 宇明, 吴吴, 杨维维, 贺德华. 催化学报), 2014, 35: 1520

[4] Nakazawa J, Smith B J, Stack T D P.J Am Chem Soc, 2012, 134: 2750

[5] Jia L X, Sun XY, Ye X Q, Zou C L, Gu H F, Huang Y, Niu G X, Zhao D Y. Microporous Mesoporous Mater, 2013, 176: 16

[6] Song M J, Zou C L, Niu G X, Zhao D Y. Chin J Catal (宋明娟, 邹成龙, 牛国兴, 赵东元. 催化学报), 2012, 33: 140

[7] Du Y C, Lan X J, Liu S, Ji Y Y, Zhang Y L, Zhang W P, Xiao F S. Microporous Mesoporous Mater, 2008, 112: 225

[8] Xiao F S. Top Catal, 2005, 35: 9

[9] Pham H N, Anderson A E, Johnson R L, Schmidt-Rohr K, Datye A K. Angew Chem Int Ed, 2012, 51: 13163

[10] Pagan-Torres Y J, Gallo J M R, Wang D, Pham H N, Libera J A, Marshall C L, Elam J W, Datye A K, Dumesic J A. ACS Catal, 2011, 1: 1234

[11] Bernardoni F, Fadeev A Y.J Colloid Interface Sci, 2011, 356: 690

[12] Herbert R, Wang D, Schomäcker R, Schlögl R, Hess C. ChemPhysChem, 2009, 10: 2230

[13] Zhao Y X, Gao C G, Li Y X, Zhang T M. Microporous Mesoporous Mater, 2009, 124: 42

[14] Castricum H L, Mittelmeijer-Hazeleger M C, Sah A, ten Elshof J E. Microporous Mesoporous Mater, 2006, 88: 63

[15] Chen G D, Wang L Z, Lei J Y, Zhang J L. Microporous Mesoporous Mater, 2009, 124: 204

[16] Jiang T L, Tao H X, Ren J W, Liu X H, Wang Y Q, Lu G Z. Microporous Mesoporous Mater, 2011, 142: 341

[17] Wang L Z, Shao Y F, Zhang J L, Anpo M. Microporous Mesoporous Mater, 2007, 100: 241

[18] Li C L, Wang Y Q, Guo Y L, Liu X H, Guo Y, Zhang Z G, Wang Y S, Lu G Z. Chem Mater, 2007, 19: 173 


\title{
Graphical Abstract
}

Chin. J. Catal., 2015, 36: 1350-1357 doi: 10.1016/S1872-2067(15)60857-9

\section{Facile solvothermal post-treatment to improve hydrothermal stability of} mesoporous SBA-15 zeolite

Chenglong Zou, Guanyu Sha, Haifang Gu, Yao Huang, Guoxing Niu* Fudan University

A simple approach was proposed to improve the hydrothermal stability of SBA-15 via solvothermal treatment by forcing $\mathrm{Si}-\mathrm{OH}$ groups in the walls close together, dehydrate, crosslink, and promote the silica condensation degree.

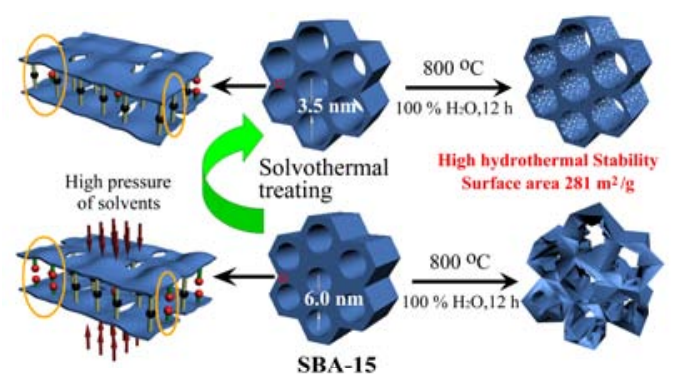

[19] Gong R H, Han L, Gao C B, Shu M H, Che S A. J Mater Chem, 2009, 19: 3404

[20] Vu X H, Steinfeldt N, Armbruster U, Martin A. Microporous Mesoporous Mater, 2012, 164: 120

[21] Liu Z Y, Wei Y X, Qi Y, Zhang S G, Zhang Y, Liu Z M. Microporous Mesoporous Mater, 2006, 93: 205

[22] Sakthivel A, Huang S J, Chen W H, Lan Z H, Chen K H, Kim T W, Ryoo R, Chiang A S T, Liu S B. Chem Mater, 2004, 16: 3168

[23] Liu Y, Zhang W Z, Pinnavaia T J. Angew Chem Int Ed, 2001, 40: 1255

[24] Do T O, Nossov A, Springuel-Huet M A, Schneider C, Bretherton J L, Fyfe C A, Kaliaguine S. J Am Chem Soc, 2004, 126: 14324

[25] Selvaraj M, Kawi S, Park D W, Ha C S. Microporous Mesoporous Mater, 2009, 117: 586

[26] Li Q, Wu Z X, Tu B, Park S S, Ha C S, Zhao D Y. Microporous Mesoporous Mater, 2010, 135: 95

[27] Selvaraj M, Kawi S. Chem Mater, 2007, 19: 509

[28] Wu Z Y, Jiang Q Wang Y M, Wang H J, Sun L B, Shi L Y, Xu J H, Wang Y, Chun Y, Zhu J H. Chem Mater, 2006, 18: 4600

[29] Zhang F Q, Yan Y, Yang H F, Meng Y, Yu C Z, Tu B, Zhao D Y.J Phys
Chem B, 2005, 109: 8723

[30] Michaux F, Carteret C, Stébé M J, Blin J L. Microporous Mesoporous Mater, 2008, 116: 308

[31] Pan D H, Yuan P, Zhao L Z, Liu N, Zhou L, Wei G F, Zhang J, Ling Y C, Fan Y, Wei B Y, Liu H Y, Yu C Z, Bao X J. Chem Mater, 2009, 21: 5413

[32] Han Y, Li D F, Zhao L, Song J W, Yang XY, Li N, Di Y, Li C J, Wu S, Xu X Z, Meng X J, Lin K F, Xiao F S. Angew Chem Int Ed, 2003, 42: 3633

[33] Galarneau A, Nader M, Guenneau F, Di Renzo F, Gedeon A.J Phys Chem C, 2007, 111: 8268

[34] Han Y, Li N, Zhao L, Li D F, Xu X Z, Wu S, Di Y, Li C J, Zou Y C, Yu Y, Xiao F S. J Phys Chem B, 2003, 107: 7551

[35] Guo W P, Li X, Zhao X S. Microporous Mesoporous Mater, 2006, 93: 285

[36] Pu H P, Han C Y, Wang H, Xu S W, Zhang L Y, Zhang Y Y, Luo Y M. Appl Surf Sci, 2012, 258: 8895

[37] Zhao D Y, Feng J L, Huo Q S, Melosh N, Frederickson G H, Chmelka B F, Stucky G D. Science, 1998, 279: 548

[38] Sindorf D W, Maciel G E.J Phys Chem, 1982, 86: 5208

[39] Senol A.J Chem Thermodyn, 2013, 67: 28

\section{改善SBA-15介孔材料水热稳定性的简单溶剂热后处理方法}

\author{
邹成龙 ${ }^{\mathrm{a}}$, 沙观宇 ${ }^{\mathrm{b}}$, 顾海芳 ${ }^{\mathrm{b}}$, 黄 曜 ${ }^{\mathrm{b}}$, 牛国兴 ${ }^{\mathrm{a}}{ }^{*}$ \\ a复旦大学化学系, 上海200433 \\ 复旦大学材料系, 上海 200433
}

摘要: 提出了一种有效改善SBA-15介孔材料水热稳定性的简单溶剂热后处理方法. SBA-15材料经环己烷、甲苯和正丁醇等有机 溶剂在 157 和 $190^{\circ} \mathrm{C}$ 密闭容器中分别处理6- $24 \mathrm{~h}$ 后, 可呈现很好的水热稳定性. 它们在 $800^{\circ} \mathrm{C}$ 经 $100 \%$ 水蒸气处理 $12 \mathrm{~h}$, 依然能保持很 好的有序介孔结构, 比表面积可高达 $192-281 \mathrm{~m}^{2} / \mathrm{g}$. 其中, 经环已烷 $190^{\circ} \mathrm{C}$ 溶剂热处理 $24 \mathrm{~h}$ 的样品表现出最优的水热稳定性. 溶剂 热处理能显著提升材料孔壁中类似 $\mathrm{Si}(\mathrm{OSi})_{2}(\mathrm{OH})_{2}$ 和 $\mathrm{Si}(\mathrm{OSi})_{3} \mathrm{OH}$ 结构的 $\mathrm{Si}-\mathrm{OH}$ 基间脱水, 形成稳定的 $\mathrm{Si}(\mathrm{OSi})_{4}$ 结构, 从而有效减少了 SBA-15材料孔壁的缺陷. 由此, 介孔材料的水热稳定性得到明显改善. 溶剂热处理对SBA-15材料水热稳定性的这种提升作用与 所用溶剂性质、处理温度以及SBA-15前驱体的类型密切相关. 其中, 以低沸点的非极性溶剂处理焙烧后的SBA-15材料表现出最 好的稳定化效果. 该方法具有简单、低能耗的特点, 其在制备高水热稳定的有序硅基介孔材料上有很好的潜在应用价值.

关键词: 介孔材料; SBA-15分子篮; 水热稳定性; 溶剂热处理; 脱水

收稿日期：2015-02-10. 接受日期：2015-03-30. 出版日期：2015-08-20.

*通讯联系人. 电话: (021)51630205; 传真: (021)51630307; 电子信箱: gxniu@fudan.edu.cn

基金来源: 国家重点基础研究发展计划(973计划, 2010CB226901, 2013CB934100); 国家自然科学基金(20890123).

本文的英文电子版由Elsevier出版社在ScienceDirect上出版(http://www.sciencedirect.com/science/journal/18722067). 